\title{
The importance of emotional
} competence and self-regulation from birth: a case for the evidence-based emotional cognitive social early learning approach

\author{
Donna K. Housman ${ }^{1,2^{*}}$ (1)
}

\author{
${ }^{*}$ Correspondence: \\ dkhousman@ \\ beginningsschool.com \\ 2 Beginnings School, 210 \\ South Avenue, Weston, MA \\ 02493, USA \\ Full list of author information \\ is available at the end of the \\ article
}

\begin{abstract}
Neuroscientific advances demonstrate that the age range from zero to 5 years old represents a critical window for both learning and teaching, which must involve the development of emotional competence and the growth of self-regulation as a foundation for long-term academic, personal, and social success, promoting mental health and well-being. Recent findings suggest that these capacities emerge from the co-regulation of empathic social and emotional interactions between a caregiver and young child. Based on this research, the present review will (a) describe the theoretical underpinnings of a childcare and development center-based social and emotional learning approach to support the growth of these foundational capacities in children from birth; (b) examine the role of co-regulation with a professional caregiver/teacher in promoting these capacities; and (c) detail how emotional cognitive social early learning, an integrative evidence-based approach, endeavors to foster these competencies through emotional communication, guidance, tools and techniques, most notably causal talk in the context of emotional experience.
\end{abstract}

Keywords: Emotional competence, Emotion regulation, Emotion knowledge, Early childhood, Teacher-child relationships, Socioemotional interventions, Co-regulation, Self-regulation, ECSEL, CTEE

There has been a proliferation of knowledge about how children develop skills that are crucial to academic and lifelong success, with educators increasingly aware of the need to integrate social and emotional learning (SEL) into their school programs. Both in the United States through state-led and federal initiatives such as Every Student Succeeds Act (ESSA) and a growing number of initiatives outside the US such as the iYes Project of ERASMUS+ in Europe (iYes Project 2016) and KidsMatter in Australia (KidsMatter 2017), SEL programs are being widely introduced, supported by recommended standards and funding for implementation. Fueling this effort has been a push toward better student outcomes and a belief that SEL can improve them. A 2013 US-based study entitled "The Missing Piece" asked educators what they thought could fix the problem of static educational achievements (Bridgeland et al. 2013). Results indicated that teachers

(C) The Author(s) 2017. This article is distributed under the terms of the Creative Commons Attribution 4.0 International License (http://creativecommons.org/licenses/by/4.0/), which permits unrestricted use, distribution, and reproduction in any medium, provided you give appropriate credit to the original author(s) and the source, provide a link to the Creative Commons license, and indicate if changes were made. 
overwhelmingly agreed that social and emotional learning is the missing piece to boost outcomes and transform our schools.

The belief that SEL can improve student outcomes has substantial evidence to support it. A meta-analysis of 213 programs found that social and emotional learning interventions increased students' academic performance by 11 percentile points, compared with students who did not participate in SEL programs (Durlak et al. 2011). These social and emotional learning programs also reduced aggression and emotional distress among students, increased helping behaviors in school, and improved positive attitudes toward self and others.

\section{Neuroscience as a theoretical underpinning for SEL in young children}

Until recently, what has been missing in this growing body of research has been the importance of social and emotional learning-and accordingly social and emotional teaching-in early childhood. Recent advances in neuroscience suggest that such learning may be most optimal prior to age six, when school typically commences. Ninety percent of the brain develops in the first 3 years during a period of plasticity (Perry 2000), in which the flexibility of neural cells and pathways alter their structure and function in response to stimulus from the environment (Nelson et al. 2013). Given that brain development is a function of the interaction between biology and experience, children's social and emotional experiences play a critical role in the growth of the brain's architecture. Supported and directed through a secure attachment with a caregiver, these social and emotional experiences inform and shape brain development and are central to behavior, learning, and health (National Scientific Council on the Developing Child 2010; Nelson et al. 2013).

This advancement in neuroscientific research comes at a time when young children are increasingly being placed in childcare. In the United States, more than half of married parents with children under five are both employed (with higher employment rates for single parents), and a significant portion of even nonemployed mothers utilize regular childcare in the US (Bureau of Labor Statistics 2016; Laughlin 2013). The Overseas Development Institute estimates that in developing countries, up to $50 \%$ of children between the ages of three and five are enrolled in childhood education programs (Samman et al. 2016). This growing need for effective early childhood education is being increasingly recognized globally. The number of countries with national multisectoral early childhood development policies increased from seven in 2000 to 68 in 2014. A report focused on how to advance early childhood development (Anderson et al. 2016) noted that since 2000, the Inter-American Development Bank has approved more than 150 projects for early childhood development, costing over $\$ 1.7$ billion (Berlinski and Schady 2015, as cited in Anderson et al. 2016). Given this landscape, an unprecedented opportunity exists to train early childhood caregivers in an SEL approach derived from our increased understanding of brain development.

Researchers generally agree upon five key competencies of SEL for school-aged children, i.e., self-awareness, self-management, social awareness, relationship skills, and responsible decision-making (Durlak et al. 2011), and that these competencies are foundational for lifelong physical and mental health (Francis and Susman 2009), as well as necessary for success in learning (Blair and Raver 2012). What we also now understand 
based on the findings of neuroscience is that nurturing relationships in early childhood are essential for the development of brain pathways and neuroendocrine systems that are prerequisites for learning, effective brain development, social-emotional functioning, and overall health (National Scientific Council on the Developing Child 2007a, b; Nelson et al. 2013; Winter and Ministerial Council for Education [MCE] 2010). More specifically, the quality, repetition, and consistency of the young child's daily learning experiences in the context of emotional and social security are essential for the development of the brain's architecture (Winter and MCE 2010), underscoring the importance of the child's relationship with early caregivers.

\section{Importance of emotional competence and self-regulation in social, emotional, and cognitive success}

To build this foundation for social and academic success, young children need to develop emotional competence (Denham 2006), i.e., the regulation of emotional expressiveness and experience, and knowledge of one's own and other's emotions (Denham et al. 2012a, b, c, d, e). Neural circuits connected with emotion regulation are highly interactive with those associated with executive functions involving attention, working memory, inhibitory control, and cognitive flexibility (National Scientific Council on the Developing Child 2004, 2007a, b), as well as problem-solving skills, rendering them central to learning during the preschool years and beyond (Blair and Razza 2007).

Young children's understanding of and ability to regulate emotion has also been shown to be clearly linked with early academic success (Leerkes et al. 2008; National Scientific Council on the Developing Child 2004). In a study of 141 three-year-old children, Leerkes et al. (2008) examined the degree to which both emotional understanding and emotional control-rated from videotapes of children completing a number of taskspredicted both academic success and socioemotional problems. Each of the predictor variables was derived from several manifest variables and then analyzed using structural equation modeling to predict scores on the letter-word identification and applied problems subtests from the third edition of the Woodcock-Johnson (Woodcock et al. 2001), as well as the raw total problems score of the Child Behavior Checklist (Achenbach and Rescorla 2000). Results demonstrated that greater emotional understanding was significantly related to greater academic performance, and that greater emotional control was significantly associated with fewer socioemotional problems.

A study by Denham et al. (2003) has demonstrated the longitudinal link between preschool emotional competence and later social competence. Participants were 143 children, aged 3 and 4 years old at the time of initial assessment. Measures of emotional competence at the initial assessment included ratings based on observations, semistructured interviews, and maternal reports. Social competence, based on peer and teacher ratings, was measured at both the initial assessment and when children were 5- to 6 years old. Using structural equation modeling of latent variables, results demonstrated that the interaction of emotional expressiveness and emotion regulation at ages 3 and 4 significantly predicted social competence measured concurrently, as well as at ages 5 and 6.

Moreover, research has demonstrated that self-regulation-defined as the ability to control and manage emotion, cognition, and behavior (Diamond 2006) - is closely 
related to emotional competence, since children use the skills of emotional competence to regulate themselves (Saarni 1997). In fact, emotion regulation is a core component of self-regulation (Murray et al. 2015), and self-regulation is critical for learning, as well as for social and academic success (Francis and Susman 2009; McClelland et al. 2010; Murray et al. 2015). Blair and Razza (2007), in a study of 141 children from 3 to 5 years old from low-income homes, demonstrated significant positive correlations between most measures of child self-regulation collected during both preschool and then later in kindergarten on the one hand, and math and literacy abilities measured in kindergarten on the other hand.

In an apparent acknowledgment of the recognized importance of SEL and self-regulation in the early years, the global Organization for Economic and Community Development (OECD) has recently introduced the International Early Learning and Child Well-being Study (IELS). This study will provide participating countries with a common framework and comparable empirical information about the early learning domains not only of emerging literacy and numeracy skills, but also self-regulation and social and emotional skills, in order to improve early learning outcomes and overall well-being for young children.

\section{The emergence of emotional competence and self-regulation in early childhood}

Several studies point to just how skills associated with emotional and self-regulation competencies emerge in children (e.g., Denham 1986; Murray et al. 2015). A child initially communicates through expressions of emotion, followed by rapid development of the ability to experience and express different emotions, as well as managing and coping with a variety of emotions (National Scientific Council on the Developing Child $2004,2007 \mathrm{a}, \mathrm{b})$. This development is influenced by a primary caregiver through a process known as "co-regulation," in which parents or other caregiving adults facilitate a child's ability to understand, express, and modulate their thoughts, behaviors, and feelings through support, coaching, and modeling in warm, responsive interactions (Schore 2003; for information regarding a short-term, attachment-based model of play therapy that draws on some related literature, the reader is referred to Munns 2015).

Self-regulation is an outgrowth of co-regulation, whereby the development of selfregulation in a child's early years can be strengthened with support, instruction, reinforcement, and coaching provided by caregivers (Murray et al. 2016b). Early childhood self-regulation develops in two phases, i.e., from birth to age two (infancy and toddlerhood), and ages three to five (preschool and pre-k; Murray et al. 2016b; see Tables 1, 2). It has been shown that a systematic and intentional approach to intervention can facilitate development in both phases, with a greater emphasis on cognition and language in the later phase (Murray et al. 2016b). Within the first phase, the infant and young toddler develop the awareness and ability to express and experience emotion within the envelope of the caregiver-child relationship. In this relationship, the caregiver is attuned to be responsive and sensitive to the emotions of the child and provides the safe and supportive environment to help label the emotions and safely express them. The manner in which the adult responds to the child with affective control through tone and tempo of voice, touch, and gaze helps infants and toddlers learn to better manage and reduce the 
intensity of their emotion on the path toward self-regulation. In the second phase, from three to 5 years, the relationship continues in this manner, but the child begins to understand and discern between and among their own emotions and those of others, as well as to deal with emotions in a regulated manner.

Research has yielded specific guidelines for early childhood interventions that enhance self-regulation. These include (a) a more intentional and targeted focus on self-regulation, in which cognitive and emotion-regulation skills and their integration are systematically taught; (b) support for caregiver's own self-regulation; and (c) instruction of caregivers to model, coach, reinforce, and support self-regulation skill support within the context of a warm and responsive relationship, i.e., "co-regulation" skills (Murray et al. 2016b).

\section{Emotional cognitive social early learning (ECSEL) What is ECSEL?}

Emotional cognitive social early learning (ECSEL) is (a) an evidence-based approach; (b) based on emotional foundations of learning and cognition; (c) informed by research in neuroscience, child development, and education; and (d) developed to facilitate the process by which children learn emotional competence and self-regulation. ECSEL is, at its core, an intervention and prevention model contextualized within the theoretical underpinnings of brain science and child development. The approach utilizes trained caregivers in a school setting to teach children 3 months -6 years the foundations of selfregulation as an outgrowth of co-regulation, most notably by teaching emotion regulation and emotion knowledge toward the development of self-regulation and positive long-term outcomes while children are in a state of emotional arousal.

Since classrooms are critical social and emotional environments for children (Zins et al. 2007), ECSEL focuses on interactions with caregivers to model, coach, and instruct young children toward the acquisition of these skills and competencies through the process of co-regulation. The approach is further supported by research in co-regulation that demonstrates that teaching and learning are an outgrowth of human interaction, particularly in the early years of development (Murray et al. 2015; Schunk and Pajares 2009). ECSEL specifically targets early childhood because the secure attachment relationship during this time promotes optimal social and emotional development (Nelson et al. 2013). For example, high-quality relationships between caregiver and child that incorporate positive responses and emotional attunement are positively correlated with students' emotion regulation (Denham et al. 2012a, b, c, d, e). ECSEL is further supported by research demonstrating that self-regulation is a cornerstone of early childhood development across all domains of behavior (Shonkoff and Phillips 2000) and by more recent research demonstrating that during this time, acquisition of both critical social and emotional skills is facilitated through co-regulation (Murray et al. 2015; Ursache et al. 2013).

\section{How ECSEL was developed}

The ECSEL approach was developed by Housman, and it is practiced at the Beginnings School and Child Development Center in Weston, Massachusetts, which she founded in 1985. The ECSEL approach has evolved over the course of Beginnings' 30-year history. 
Table 1 Promoting the growth of self-regulation development and co-regulation from birth through age 2: ECSEL approach. Adapted from Murray et al. (2016b)

\begin{tabular}{|c|c|c|c|}
\hline Developmental stage & $\begin{array}{l}\text { Characteristics of self- } \\
\text { regulation }\end{array}$ & $\begin{array}{l}\text { How caregivers can pro- } \\
\text { vide co-regulation }\end{array}$ & $\begin{array}{l}\text { ECSEL techniques } \\
\text { and tools }\end{array}$ \\
\hline Infancy (birth to age 1) & $\begin{array}{l}\text { Orient attention away from } \\
\text { stressors } \\
\text { Engage caregivers as } \\
\text { resources for comfort } \\
\text { Begin to self-soothe }\end{array}$ & $\begin{array}{l}\text { Interact in warm respon- } \\
\text { sive ways } \\
\text { Anticipate and respond } \\
\text { quickly to child's needs } \\
\text { Provide physical and } \\
\text { emotional comfort when } \\
\text { child is stressed } \\
\text { Modify environment to } \\
\text { decrease demands/stress }\end{array}$ & $\begin{array}{l}\text { Physiological techniques } \\
\text { CTEE }\end{array}$ \\
\hline $\begin{array}{l}\text { Toddlerhood (ages 1-2, } \\
\text { approximately) }\end{array}$ & $\begin{array}{l}\text { Begin to select and shift } \\
\text { attention (attentional } \\
\text { control) } \\
\text { Adjust behavior to achieve } \\
\text { simple goals } \\
\text { Delay gratification and } \\
\text { inhibit responses for } \\
\text { short periods when there } \\
\text { is structure and support } \\
\text { Emotions are stronger than } \\
\text { cognitive regulation } \\
\text { Feelings of attachment } \\
\text { support prosocial goals }\end{array}$ & $\begin{array}{l}\text { Reassure/calm child when } \\
\text { upset by removing child } \\
\text { from situations or speak- } \\
\text { ing calmly and giving } \\
\text { affection } \\
\text { Model self-calming strate- } \\
\text { gies } \\
\text { Teach rules and re-direct- } \\
\text { ing to regulate behavior }\end{array}$ & $\begin{array}{l}\text { CTEE } \\
\text { Peace Corner } \\
\text { Mood Mirror } \\
\text { Emotion Chart } \\
\text { Emotion Books }\end{array}$ \\
\hline
\end{tabular}

Table 2 Promoting the growth of self-regulation development and co-regulation for ages 3-5: ECSEL approach. Adapted from Murray et al. (2016b)

\begin{tabular}{|c|c|c|}
\hline Characteristics of self-regulation & $\begin{array}{l}\text { How caregivers can provide co- } \\
\text { regulation }\end{array}$ & ECSEL techniques and tools \\
\hline $\begin{array}{l}\text { Focused attention increases but it still } \\
\text { brief } \\
\text { Begin to use rules, strategies, and plan- } \\
\text { ning to guide behavior appropriate } \\
\text { to situation } \\
\text { Delay gratification and inhibit } \\
\text { responses for longer periods } \\
\text { Perspective-taking and empathy sup- } \\
\text { port prosocial goals } \\
\text { Language begins to control emotional } \\
\text { responses and actions } \\
\text { Tolerate some frustration and distress } \\
\text { apart from caregiver (self-calming } \\
\text { skills emerge) }\end{array}$ & $\begin{array}{l}\text { Model, prompt, and reinforce (or } \\
\text { "coach") self-calming strategies when } \\
\text { child is upset } \\
\text { Instruct and coach use of words to } \\
\text { express emotion and identify solu- } \\
\text { tions to simple problems } \\
\text { Coach rule-following and task comple- } \\
\text { tion } \\
\text { Provide external consequences to sup- } \\
\text { port emerging self-regulation skills }\end{array}$ & $\begin{array}{l}\text { Emotion Thermometer } \\
\text { Peace Table } \\
\text { Peace Corner } \\
\text { CTEE } \\
\text { Emotion Chart } \\
\text { Emotion Books } \\
\text { SheHeMe }\end{array}$ \\
\hline
\end{tabular}

The growing body of research that shows a link between early academic success and young children's understanding of emotion (Ashiabi 2000; Leerkes et al. 2008) provides support for ECSEL's focus on developing emotional competence on the path toward selfregulation for positive long-term outcomes. Specifically, results have demonstrated that children with poor social-emotional competence and self-regulation have more difficulty transitioning to school, and they are at increased risk for low academic achievement, emotional and behavioral problems, peer rejection, and school dropout (Denham 2006; McClelland et al. 2006). 
In this context, ECSEL was grounded in Salovey and Mayer's (1990) and Mayer et al. (2008) theoretical model of emotional intelligence. This model delineates abilities that include (a) perceiving, appraising, and expressing emotions, (b) using emotions to facilitate thinking, (c) understanding the antecedents and consequences of emotions, and (d) regulating emotions in self and others, abilities that more recently have been aggregated in the term "emotional competence" (Denham 1998; Denham et al. 2011). ECSEL was designed to promote these four underlying principles of emotional intelligence, through the application of developmentally appropriate techniques and tools that begin with emotion identification and recognition of appropriate expression and progress into understanding cause, effect, and regulation of emotion (see Tables 1, 2, 3, as well as Fig. 1).

Extant literature on the importance of self-regulation for learning (McClelland et al. 2010) has also informed the development of ECSEL. ECSEL supports the development of self-regulation capacities that are comprised of cognitive regulation, emotion regulation, and behavioral regulation (Murray et al. 2015). Through developmentally appropriate ECSEL tools and techniques, the caregiver/teacher uses direction, modeling, and guidance inherent to effective co-regulation in promotion of children's internalization of skills in self-regulation/self-control (see Tables 1, 2, 3, as well as Fig. 1). These skills are also foundational to emerging executive functioning skills that, too, are essential for learning (Thompson 2009).

\section{ECSEL versus Other SEL Interventions}

Recent research evidences that social and emotional interventions are effective in supporting children's social and emotional development (Schultz et al. 2011). In a pilot study of 18 preschool children aged 3-5 years at a family service center, Schultz et al. (2011) implemented an 8-week social-emotional learning program. Results demonstrated significant pre-post improvement in two subscales of teacher ratings of children's social and behavioral functioning. Of the remaining 11 subscales that did not demonstrate statistically significant change (likely since a conservative Bonferonni correction was used to control for Type I error), the improvement on six subscales nevertheless fell in the range of a medium effect size.

ECSEL comes at a time when, despite growing awareness of the importance of evidence-based practice to support social and emotional competencies (Denham et al. 2013; Shonkoff and Phillips 2000), few evidence-based approaches that target emotional competence and self-regulation in the first few years of a child's life have emerged, particularly programs that are teacher-led (Denham et al. 2003; Murray et al. 2016a). At present, social and emotional learning programs are mainly offered to children 5 years and older in a school setting, missing the key developmental window of early childhood neuroplasticity (Wilson et al. 2012). Perhaps more strikingly, given the increasing numbers of very young children (birth through two) spending time in childcare, there is little research on interventions implemented by or for childcare providers (Murray et al. 2016a). Programs such as Promoting Alternative Thinking Strategies (PATHS), Research-Based Developmentally Informed (REI), Incredible Years (IY), and Chicago School Readiness Project (CSRP) offer interventions primarily to Head Start and highrisk, high-poverty, or high-crime populations to assist preschool-aged children in the 
Table 3 Content and objectives of the emotional cognitive social early learning (ECSEL) curriculum (ages 0-6)

Tool
CTEE (causal talk in the context of emotional experi-
ence)
Emotions chart/use gender neutral SheHeMes $^{\text {TM }}$
Figures $^{\text {a }}$

Objectives

The heart of the ECSEL curriculum. Teachers use during the heat of the moment, while a child is in the midst of emotional arousal

Increase emotional expressiveness, verbal and nonverbal in children Increase emotion regulation in children Increase communication about emotions Manage one's own emotions Understand one's own and other's emotions Figures $^{\mathrm{a}}$

Designed to help children start to address cause and effect when it comes to their emotions and behavior Learn to label their emotion Increase understanding of certain situations that can make them feel a particular way Increase understanding of cause (a situation) and effect (emotional response)

Emotion books

Representations of emotions (personalized or published) Condition children to recognize emotions and talk about them (causal talk)

Learn to label their emotions

Match facial expressions to different emotions

Learn to identify cause of emotions

Peace Table (3 years and above)/Peace Corner (toddler and preschoolers)

Mood mirror

Provides children with repeated experiences and opportunities to develop and strengthen emotion regulation and executive functioning skills. During a visit to the Peace Table children

1. Physiologically regulate their body (deep breaths, "calm down" bottles, squishy balls, counting)

2. Talk about the problem

3. Express their own emotions using the emotions thermometer to define the intensity of the emotion

4. Listen and identify the other child's emotion

5. Think of alternative ways to solve the problem

6. Choose the best plan for problem resolution

7. Follow through with an alternative solution and enact it

8. Revisit the emotions thermometer and identify emotions after the resolution

For a successful resolution, children will need to

1. Identify and discern emotions (i.e. knows why he/she is feeling sad versus angry)

2. Express emotion in constructive ways, either verbally or with gestures (such as hugging)

3. Regulate their emotions

4. Talk about the problem at hand

5. Be sensitive and understand the emotions of others

Multisensory approach to teach infants and children about different types of feelings

Helps to develop self-awareness

Support children in identifying and labeling emotions (for children as young as 3 months)

Teachers provide comfort or ways to express it in a constructive way

Emotion thermometer/use gender neutral SheHeMe ${ }^{\mathrm{TM}}$ Figures $^{\mathrm{a}}$

Uniquely designed component of ECSEL, used during heightened emotional states

Identify the emotion the child has in the heat of the moment

Express the intensity of that emotion

Make it easier for children to recognize a particular emotion

Learning the words (spelling) for different emotions 
Table 3 continued

\begin{tabular}{ll}
\hline Tool & Objectives \\
\hline $\begin{array}{l}\text { Physiological regulation techniques (breathing } \\
\text { exercises, lovies, family pictures, tone and volume, } \\
\text { pillows, squishy balls) }\end{array}$ & $\begin{array}{c}\text { External and internal influences to help calm emotions. } \\
\text { Children learn } \\
\text { To calm/regulate their bodies when experiencing } \\
\text { intense emotions } \\
\text { Redirect any psychical actions toward peers } \\
\text { Independently seek out ways to comfort and regulate } \\
\text { themselves } \\
\text { Learn different ways to relax }\end{array}$ \\
\hline
\end{tabular}

${ }^{a}$ This refers to characters designed to exemplify different emotions that children use to express/reflect their own emotions

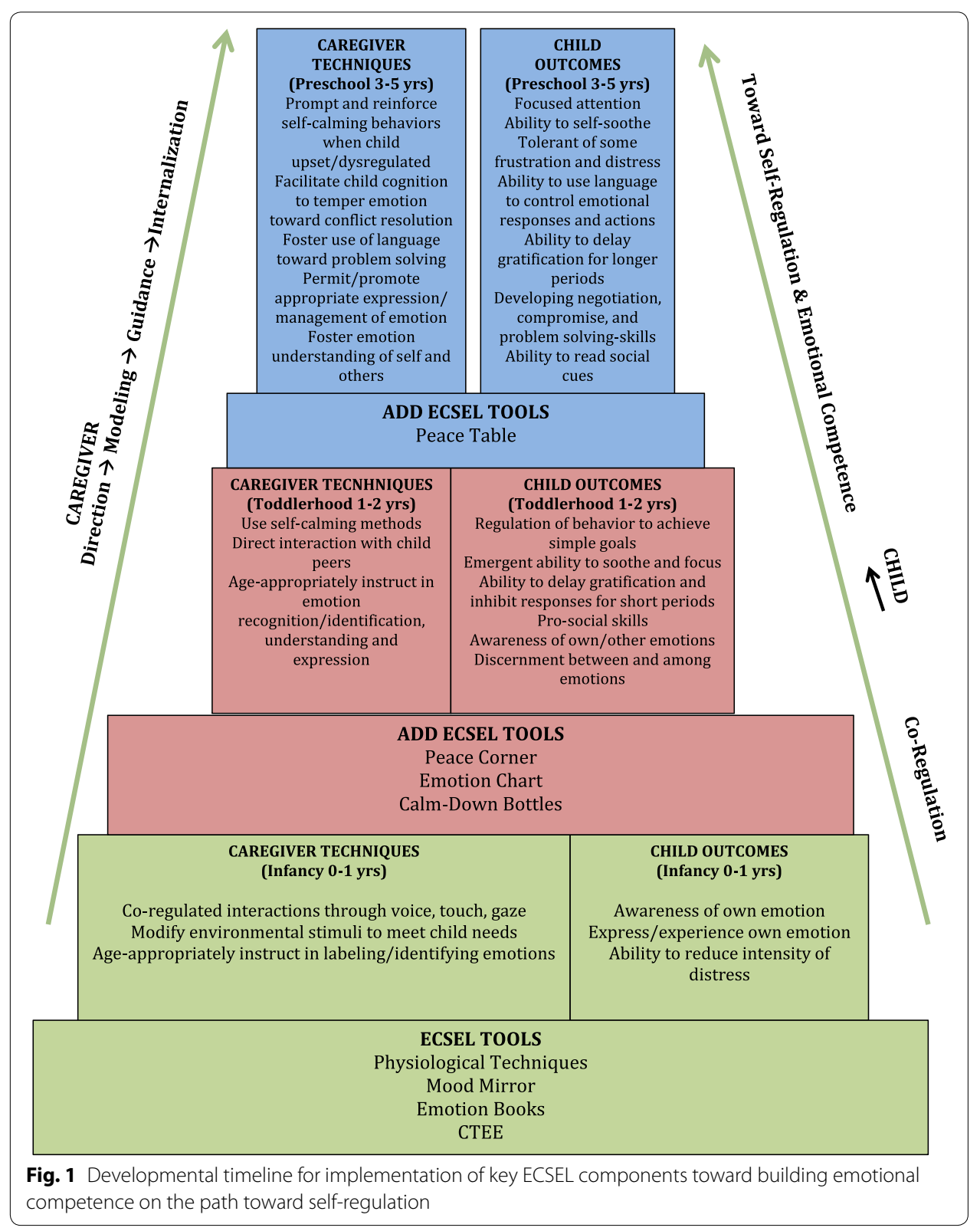


development of Social and Emotional Learning (SEL) through instruction and discussion (Barton et al. 2014; McCabe and Altamura 2011; Murray et al. 2015, 2016a; What is SEL? 2016). The Teaching Pyramid (CSEFEL) promoting SEL is one of the few programs which provides teaching modules directed at children beginning in infancy, but additional research examining the efficacy of this model in improving social and emotional outcomes within the early childhood setting is still needed, particularly among children at risk of behavioral difficulties (McCabe and Altamura 2011).

\section{How ECSEL is unique}

Unlike many of the aforementioned SEL early childhood programs that offer a defined number of time-limited, structured lesson plans throughout the year, the ECSEL approach is woven daily throughout the entire years' curriculum for all children of diverse cultures (see Fig. 1 for a diagram of key components and causal relationships in ECSEL). Equally important, ECSEL begins from birth. In addition, ECSEL maintains a unique emphasis on current emotional situations as an opportunity to learn more appropriate emotion-regulation strategies (Cole et al. 2009), particularly using co-regulation by caregivers to support self-regulation (Best et al. 2011; Blair and Razza 2007; Cohen et al. 2005; Denham et al. 2012d; Murray et al. 2015).

\section{ECSEL and emotional competence}

ECSEL helps young children from birth develop emotional competence through contingent communication, in which the internal state of the child is perceived, acknowledged, made sense of, and responded to by the caregiver, a phenomenon that is found across cultures (Trevarthen 2009). It is through such shared experiences that children learn how to regulate their own emotional arousal (Siegel 2012).

\section{ECSEL and causal talk}

Knowing how to help children understand and regulate emotion-and working together with both teachers and parents to promote that understanding-is therefore fundamental to ECSEL. It has been shown that when parents help children develop particular skills to deal with their emotions, children are more successful in managing and coping with their own emotions and those of others (Gottman 2000). It also has been demonstrated that one important way in which children develop such skills is through adult-child conversations around emotions, known as causal talk (CT; Salmon et al. 2013). Causal talk is therefore one important component of ECSEL.

Causal talk about emotions, referred to in some studies as emotion cause talk (Brown and Dunn 1996; Salmon et al. 2013), is commonly broken down into three categories: unelaborated comments about emotions; explanations of the causes and consequences of emotions; and empathy-related statements (Dunn and Brown 1993). ECSEL trains teachers to use all of these opportunities to enhance emotion knowledge, based on the precept that children's emotional competence can be promoted using the current emotional situation as an opportunity to learn more appropriate emotion-regulation strategies (Cole et al. 2009). In the early stage of children's development, the caregiver uses language and communication around emotion to build emotion knowledge and emotion regulation through modeling, teacher-led instruction, and nonverbal reciprocal 
communication. As the young child matures, this communication becomes more verbal with the teacher providing more clearly defined tasks, expectations, perspective taking, and consequence. For instance, in the older children, emotion knowledge is enhanced when children participate in conversation that encourages their use of emotion language after listening to a story, underscoring that the use of emotion language during causal talk in teaching can enhance emotion knowledge (Gavazzi et al. 2011). This approach is supported by evidence that demonstrated, on the one hand, the relation between emotion cause talk by children (or children and their mothers) and emotional understanding on the other (Brown and Dunn 1996; Salmon et al. 2013).

Specifically, supporting this approach is a study by Salmon et al. (2013) that randomly assigned 53 children between the ages of three and four to one of three groups, balanced within-preschools and for gender: (a) emotion cause talk, (b) non-emotion cause talk that focused on general causal relationships, or (c) a no-training control. Results indicated that children in the emotion cause talk condition reported significantly more combined spontaneous emotion labels and causes than the other two groups, using codes for emotional language from an emotion narrative task (Garner et al. 1997), although there were not significant between-group differences for some other components of emotion knowledge.

In another study, Brown and Dunn (1996) demonstrated in a sample of 47 children that increased frequency of child causal talk (as well as increased frequency of causal talk by both child and mother) predicted greater understanding of emotional ambivalence 3 years later. Taken together, then, the results of Brown and Dunn (1996) and Salmon et al. (2013) suggest that children's causal talk may have a unique role in the development of emotional competence.

\section{ECSEL and CTEE}

To date, research has primarily focused on causal talk (CT) outside the child's immediate emotional experience (Brown and Dunn 1996; Salmon et al. 2013). What uniquely distinguishes ECSEL is that children learn to talk about emotions through lived emotional experiences during a state of emotional arousal, known as causal talk in the context of emotional experience (CTEE). CTEE in ECSEL consists of not only identifying and labeling an emotion but also managing intense emotions, including stress and anxiety, in the heat of the moment, when the child is in the midst of emotional arousal. Teachers use CTEE as learning opportunities to increase children's emotional understanding, expressiveness, and emotional, cognitive, and behavioral regulation. A literature review did not find any evidence of the use of CTEE in early education. ECSEL, however, uses CTEE in conjunction with other supporting developmentally appropriate tools and techniques to optimize these moments of emotion arousal as a way of helping children manage the stress, anxiety, and worry that confronts them daily. Sensitive, attuned, and responsive ECSEL teachers offer the experiences that help build emotional and social competencies based on the child's developmental stage, which then serve as a basis for developing emotional competence and ultimately self-regulation (see Table 3 ). 


\section{Parent and teacher training in ECSEL}

Teacher training and daily communication between teachers and parents is an important facet of ECSEL. Parents are provided with daily verbal updates as well as written summaries of their child's progress in developing emotional competence and self-regulation. The techniques and tools used in teacher training also are communicated to parents through discussion groups, seminars, and direct consultation, so that both teacher and parents have shared knowledge, expectations, and techniques.

Parents' points of view in the ECSEL model are always respected. ECSEL does not prescribe or proscribe parenting behavior, but instead works off the assumption that the more information parents learn about their role in children's development and in promoting emotional competence and self-regulation, the more competent they will become in making meaningful and purposeful decisions to facilitate their children's growth within the framework of their own culture and values.

ECSEL trains teachers how best to understand and promote their students' emotional competence, how to use appropriate tools and techniques, and how to increase teachers' understanding of their emotionality. Specifically, qualified, licensed therapists work directly with educators to learn to assess their own abilities to accurately perceive, appraise, and express emotions; understand emotions and emotional knowledge, such as labeling feelings; and reflect, manage, and regulate emotions to promote emotional and intellectual growth (Kremenitzer and Miller 2008).

Reflective supervision provided by the aforementioned therapists is integral to this ECSEL training approach, with assessments conducted both at the start of the training programs and on an ongoing weekly basis, outside the classroom through review of classroom video recordings, peer reviews, and case presentation analysis. By increasing teachers' awareness of their own emotions (self-awareness), sensitivity to the emotions of others (empathy), and ability to manage the intensity of their emotions (emotion regulation), teachers are better able to facilitate the self-regulation of the children. Importantly, teachers also observe and monitor the development of their students' emotional competence to better assess the effectiveness of their interactions within the classroom. Throughout the year, teachers also meet weekly with a licensed therapist who serves as a mentor in helping teachers address the social and emotional development of their students, as well as themselves. Training includes discussion of constructive and destructive responses to situational challenges. Through observation and video recording, ECSEL training also is able to highlight positive and negative examples of modeling, reactions, and communication between and among teachers and children.

\section{ECSEL tools, techniques, and the classroom environment}

ECSEL trains teachers in the use of specific tools and techniques (see Table 3). An "Emotions Chart," introduced when children are approximately 14 months, is one such tool. The chart helps children identify their emotions and connect their feelings, particularly while in a state of aroused emotion, with their life experience. In every classroom, children are encouraged to use the Emotions Chart at the beginning and at the end of the day. During circle time when teachers gather the children together, they ask children about the emotion they are experiencing and its possible cause. For younger children who have not yet acquired language skills, a "Mood Mirror" is placed nearby so that 
children can associate what is on their face to the emotion they are experiencing. ECSEL also includes visual representations of emotions-whether through Emotion Books, Mood Mirrors, or gender-neutral designed figures named SheHeMes ${ }^{\mathrm{TM}}$ placed on Emotion Thermometers to measure emotional intensity-to help children better understand not only how to identify and understand emotions but also to learn that emotions are kinetic rather than static, influenced by environmental experiences (see Table 3).

\section{Language as regulator in ECSEL}

Given that language serves an organizing functioning in the regulation of emotion (Denham et al. 2012a, b, c, d, e), words are important tools in ECSEL. Once children begin to acquire language, ECSEL teachers increasingly help children develop coherent scripts about their emotional experience, which in turn provide the vocabulary necessary to approach, manage, resolve, and cope with conflicts. The following vignette provides an illustration of such an approach.

During free time, two toddlers, Hannah (22 months) and Eric (24 months), are engaged in a conflict. Hannah startles her classmate Eric by suddenly drawing on his picture. Eric then breaks down into tears, leaving Hannah confused. The teacher steps in to help the children resolve the conflict in the heat of the moment. The teacher asks each child to express in words what the problem is, or if the child does not yet have the words, the teacher will model a response by putting into words what she sees happening between the children. The teacher then helps the children identify the emotion each child is experiencing and finally helps both children come up with alternative constructive ways to resolve the problem. To achieve a constructive solution, the teacher articulates a choice: Hannah can draw on her own, or the two can draw together. Eric and Hannah ultimately resolve the problem by choosing to draw on their own.

This example reflects several ECSEL principles. The teacher works to help the children constructively express an emotion using words rather than action, think about alternative ways to resolve the problem, make an informed decision between two articulated choices, and develop social skills by understanding the emotion of another. Using words in this manner, instead of maladaptive action, promotes internal organization and selfcontrol (Vallotton and Ayoub 2011).

We can see the results of such an approach with a 3-year-old student named Miller, who one afternoon intercepted another teacher while she was walking through the classroom. Miller had been enrolled in the ECSEL-based program for a year, and approaching the teacher, he told her he had something to share with her. "I am so frustrated," he said, using a specific word to express the emotion he was experiencing. When asked why, he responded that during clean-up time, his classmate Lizzy had knocked over his blocks and that he felt "very frustrated" at the time. When asked how he resolved the situation, Miller went on to explain proudly that he used his words and told her to stop, but "she did not listen." Questioned further, he explained that he went to his teacher, who then told Lizzy to freeze her body. "Lizzie listened," he explained. "She used her listening ears, and then I said, 'let's go to the Peace Table (see below for details about the Peace Table) and work out the problem together."'

In this example, Miller not only successfully used his words to express his emotionboth in the heat of the moment and in his recounting-but also enlisted the support 
of his teacher in helping his classmate to do the same. Teaching children how to manage and deal with their emotions in the heat of the moment can potentially be far more effective than learning about conflicts that happen in displaced situations (i.e., from a storybook, movie, or television show).

We should note, however, that the level of adult involvement in this example might be more typical of American than other cultures, and even when comparted with other cultural contexts within the United States (Tobin et al. 1989). ${ }^{1}$ In their ethnographic study of three preschools (one in Japan, a second in China, and a third in the US), for example, Tobin and colleagues (1989) noted that in the Japanese preschool, peer interactions were believed to exert a more positive influence on child behavioral control than interactions with teachers.

\section{The ECSEL Peace Table and the Peace Corner}

Two essential components of the classroom involve the Peace Corner for toddlers and the aforementioned Peace Table for preschoolers. The Peace Table is used to help children achieve interpersonal problem solving through emotion regulation and critical thinking skills. The process that takes place at the Peace Table involves a structured negotiation between children involved in a conflict, and it results in identifying possible solutions to the problem and enacting the agreed-up solution. Similarly, the Peace Corner for younger children involves adults conversing with children through CTEE, and encouraging children to express verbally what may have caused strong emotional reactions, while exploring alternative ways of resolving the issue. Physiological regulation techniques are also integrated into ECSEL, which involve use of breathing techniques, squishy balls, pillows, calm-down bottles or other tools.

\section{Measuring success in ECSEL}

Integral to the ECSEL approach is the measurement of children's progress in developing their emotional competence and self-regulation. Teachers evaluate student progress preand post-intervention through administration of the Devereux Early Childhood Assessments (DECA)-Infant-Toddler and Preschool-2nd edition, which measure the domains of attachment, initiative, and self-regulation (LeBuffe and Naglieri 2012; Mackrain et al. 2007) as well as several other psychometric measures that assess emotional competence and empathy.

\section{Limitations}

ECSEL was developed and implemented in a particular cultural context, i.e., in working with middle-to-upper class families in Western society. ${ }^{2}$ Within this context, the emphasis, for example, on verbal expression, independent selfhood, and dyadic relational constellations are consistent with the cultural assumptions of many of the teachers, parents, and children who have thus far used the approach. In a different locale, it remains to be seen whether these assumptions might require adaptation to fit the particular

\footnotetext{
${ }^{1}$ I am grateful to one of the anonymous reviewers who raised the issues discussed in this paragraph and directed me to Tobin et al. (1989)

2 I am grateful to one of the anonymous reviewers who raised the issues discussed in this paragraph.
} 
assumptions of the prevailing culture. Within all cultures, however, the self is expressed to varying degrees through action, such as crying, movement, and gestures (e.g., Elfenbein and Ambady 2002; Sauter et al. 2010). The goal of ECSEL is to transfer that action into expressive forms (i.e., gestures, sign language, and emotion talk) so that children are better able to label, understand, and manage their emotion in a more organized and meaningful way, while respecting different cultural norms and values. Although we have not yet applied ECSEL outside the United States, it has been used with Beginnings' multicultural population that includes native English, Mandarin, Korean, Italian, Greek, Farsi, Spanish, and Hindi speakers who originate from diverse cultures. As an illustration, we observed improvement in self-regulation skills at the end of the school year in our program by a 4-year-old boy who had moved from Brazil, was the son of a house cleaner, spoke no English, and arrived each morning at Beginnings with a cup of coffee. The boy had joined our program exhibiting highly dysregulated behavior, such as hitting, yelling, throwing objects, and withdrawing when he did not achieve his goals. After 6 months of working with the child and his mother, the boy's teacher observed the child exhibiting significant positive change in constructively identifying, expressing, and understanding factors contributing to his intense emotion and its effect, rechanneling his action into more effective peer communication, heightened initiative in problem solving, and motivation for learning.

As noted above, given the fact that the parents who participated in ECSEL were primarily middle/upper middle class, the degree to which our program can be applied to families of lower income levels cannot be definitively determined. Nevertheless, there is evidence in the literature that quality early childhood education can positively affect outcomes for disadvantaged students (Elango et al. 2015), suggesting that such programs can effectively address potential deleterious effects of lower socioeconomic status on effective program implementation and support. Taken together with the fact that ECSEL proactively counsels and guides parents as socializers in the promotion of critical emotional, cognitive, and social skills, it is not unreasonable to suggest that this program has the potential to positively influence outcomes with children from families of lower socioeconomic status. Further research, however, on the potential role of socioeconomic class in this context is clearly needed.

\section{Conclusion}

Children with poor social-emotional competence and self-regulation not only appear to have more difficulty transitioning to school, but they also are at increased risk for low academic achievement, emotional and behavioral problems, peer rejection, and school dropout (Denham 2006; McClelland et al. 2006). Moreover, children who learn socialemotional skills early in life tend to be more self-confident, trusting, empathic, intellectually inquisitive, competent in using language to communicate, and better capable of relating well with others (Cohen et al. 2005).

ECSEL, based on emotional foundations of learning and cognition, aims to help young children from birth develop emotional competence on the path toward effective selfregulation. ECSEL can begin to teach emotional competence to children as young as infants, in an effort to enhance emotion regulation and self-regulation and to promote a positive sense of self, mental health, and well-being. 
Given the paucity of research conducted in classroom settings with infants and toddlers and, in particular, about how early childhood educators promote emotional competence among children, it is crucial to develop, explore, and implement programs beginning from birth that employ a variety of techniques focused on emotional and selfregulatory skills in young children. ECSEL is one such program.

As the present paper illustrates, evidence exists that an approach such as ECSEL may have long-term implications for children's mental health, well-being, and success and-pending the results of ongoing and future research-could therefore be recommended for integration into early childhood education globally. At the same time, of course, ECSEL is not a panacea and cannot guarantee far-reaching societal changes. Further research and field application, however, will clarify the nature of its proximal benefits (i.e., post-intervention outcomes), point to the potential for distal benefits (i.e., long-term outcomes), and ideally provide the foundation for future application of this approach at a broader, societal level.

Author details

${ }^{1}$ Boston University School of Medicine, Boston, USA. ${ }^{2}$ Beginnings School, 210 South Avenue, Weston, MA 02493, USA.

Acknowledgements

The author would like to thank Dr. Marc Diener for his comments on a draft of this manuscript.

\section{Competing interests}

I am the Founder and CEO of the Beginnings School, whose ECSEL program is the focus of this manuscript. This ECSEL approach is being trademarked as begin to... ECSEL ${ }^{\mathrm{TM}}$, as is the small designed figure Sheheme ${ }^{\mathrm{TM}}$ and other program tools that I developed, all of which are only used at the Beginnings School. As such, I do receive a nominal salary in my role at Beginnings School. I have no nonfinancial competing interests to declare in relation to this manuscript.

\section{Availability of data and materials}

Not applicable.

Consent for publication

Not applicable.

Ethics approval and consent to participate

Not applicable.

Funding

I received no funding for the research reported in this manuscript.

\section{Publisher's Note}

Springer Nature remains neutral with regard to jurisdictional claims in published maps and institutional affiliations.

Received: 4 October 2016 Accepted: 16 November 2017

Published online: 28 November 2017

\section{References}

Achenbach, T. M., \& Rescorla, L. A. (2000). Manual for the ASEBA preschool forms and profiles. Burlington, VT: University of Vermont, Department of Psychiatry.

Anderson, C. T., Behrman, J. R., Bhutta, Z. A., Black, M. M., Britto, P. R., Cerezo, A., \& Yousfazi, A. (2016). Advancing early childhood development: From science to scale. The Lancet. Retrieved from http://www.thelancet.com/pb-assets/Lancet/ stories/series/ecd/Lancet_ECD_Executive_Summary.pdf.

Ashiabi, G. S. (2000). Promoting the emotional development of preschoolers. Early Childhood Education Journal, 28(2), 79-84. https://doi.org/10.1023/A:1009543203089.

Barton, E. E., Steed, E. A., Strain, P., Dunlap, G., Powell, D., \& Payne, C. J. (2014). An analysis of classroom-based and parent-focused social-emotional programs for young children. Infants \& Young Children, 27(1), 3-29. https://doi. org/10.1097/IYC.0000000000000001.

Berlinski, S., \& Schady, N. (2015). The early years: Child well-being and the role of public policy. New York, NY: Palgrave Macmillan.

Best, J. R., Miller, P. H., \& Naglieri, J. A. (2011). Relations between executive function and academic achievement from ages 5 to 17 in a large, representative national sample. Learning and Individual Differences, 21(4), 327-336. https://doi. org/10.1016/j.lindif.2011.01.007. 
Blair, C., \& Raver, C. C. (2012). Child development in the context of adversity: Experiential canalization of brain and behavior. American Psychologist, 67(4), 309. https://doi.org/10.1037/a0027493.

Blair, C., \& Razza, R. P. (2007). Relating effortful control, executive function, and false belief understanding to emerging math and literacy ability in kindergarten. Child Development, 78(2), 647-663. https://doi. org/10.1111/j.1467-8624.2007.01019.x.

Bridgeland, J., Bruce, M., \& Hariharan, A. (2013). The missing piece: A national survey on how social and emotional learning can empower children and transform schools. Washington, DC: Civic Enterprises. Retrieved from http://www. civicenterprises.net/MediaLibrary/Docs/CASEL-Report-low-res-FINAL.pdf.

Brown, J. R., \& Dunn, J. (1996). Continuities in emotion understanding from three to six years. Child Development, 67(3), 789-802. https://doi.org/10.1111/j.1467-8624.1996.tb01764.x.

Bureau of Labor Statistics. (2016). Employment characteristics of families - 2015 [News Release]. Retrieved from https:// www.bls.gov/news.release/archives/famee_04222016.pdf.

Center on the Developing Child (2011). Building the brain's "air traffic control" system: How early experiences shape the development of executive function (Working Paper No. 11). Retrieved from http://www.developingchild.harvard.edu.

Cohen, J., Onunaku, N., Clothier, S., \& Poppe, J. (2005). Helping young children succeed: Strategies to promote early childhood social and emotional development. Washington, DC: National Conference of State Legislatures.

Cole, P. M., Dennis, T. A., Smith-Simon, K. E., \& Cohen, L. H. (2009). Preschoolers' emotion regulation strategy understanding: Relations with emotion socialization and child self-regulation. Social Development, 18(2), 324-352.

Denham, S. A. (1986). Social cognition, prosocial behavior, and emotion in preschoolers: Contextual validation. Child Development, 57(1), 194-201. https://doi.org/10.2307/1130651.

Denham, S. S. (1998). Emotional development in young children. New York, NY: Guilford Press.

Denham, S. (2006). Social-emotional competence as support for school readiness: What it is and how do we assess it? Early Education and Development, 17(1), 57-89. https://doi.org/10.1207/s15566935eed1701_4.

Denham, S. A., Blair, K. A., DeMulder, E., Levitas, J., Sawyer, K., Auerbach-Major, S., et al. (2003). Preschool emotional competence: Pathway to social competence? Child Development, 74(1), 238-256. https://doi.org/10.1111/1467-8624.00533.

Denham, S. A., Bassett, H., Mincic, M., Kalb, S., Way, E., Wyatt, T., et al. (2012a). Social-emotional learning profiles of preschoolers' early school success: A person-centered approach. Learning and Individual Differences, 22(2), 178-189. https://doi.org/10.1016/j.lindif.2011.05.001

Denham, S. A., Bassett, H. H., Thayer, S. K., Mincic, M. S., Sirotkin, Y. S., \& Zinsser, K. (2012b). Observing preschoolers'socialemotional behavior: Structure, foundations, and prediction of early school success. The Journal of Genetic Psychology, 173(3), 246-278. https://doi.org/10.1080/00221325.2011.597457.

Denham, S. A., Bassett, H. H., Way, E., Mincic, M., Zinsser, K., \& Graling, K. (2012c). Preschoolers' emotion knowledge: Selfregulatory foundations, and predictions of early school success. Cognition and Emotion, 26(4), 667-679. https://doi. org/10.1080/02699931.2011.602049.

Denham, S., Bassett, H., \& Zinsser, K. (2012d). Early childhood teachers as socializers of young children's emotional competence. Early Childhood Education Journal, 40, 143. https://doi.org/10.1007/s10643-012-0504-2.

Denham, S. A., Warren-Khot, H. K., Bassett, H. H., Wyatt, T., \& Perna, A. (2012e). Factor structure of self-regulation in preschoolers: Testing models of a field-based assessment for predicting early school readiness. Journal of Experimental Child Psychology, 111(3), 386-404. https://doi.org/10.1016/j.jecp.2011.10.002.

Denham, S. A., Way, E., Kalb, S. C., Warren-Khot, H. K., \& Bassett, H. H. (2013). Preschoolers'social information processing and early school success: The challenging situations task. British Journal of Developmental Psychology, 31(2), 180-197. https://doi.org/10.1111/j.2044-835X.2012.02085.x.

Denham, S. A., Zinsser, K., \& Bailey, C. S. (2011). Emotional intelligence in the first five years of life. Encyclopedia on Early Childhood Development. Retrieved from http://www.child-encyclopedia.com/sites/default/files/textes-experts/ en/638/emotional-intelligence-in-the-first-five-years-of-life.pdf.

Diamond, A. (2006). The early development of executive functions. In E. Bialystok \& F. I. M. Graik (Eds.), Lifespan cognition: Mechanisms of change (pp. 70-95). Oxford, England: Oxford University Press.

Dunn, J., \& Brown, J. R. (1993). Early conversations about causality: Content, pragmatics and developmental change. British Journal of Developmental Psychology, 11(2), 107-123. https://doi.org/10.1111/j.2044-835X.1993.tb00591.x.

Durlak, J., Weissberg, R. P., Dymnicki, A. B., Taylor, R. D., \& Schellinger, K. B. (2011). The impact of enhancing students'social and emotional learning: A meta-analysis of school-based universal interventions. Child Development, 82(1), 405-432. https://doi.org/10.1111/j.1467-8624.2010.01564.x.

Elango, S., Garcia, J. L., Heckman, J. J., \& Hojman, A. (2015). Early childhood education (NBER Working Paper \# 21766). Cambridge, MA: National Bureau of Economic Research.

Elfenbein, H. A., \& Ambady, N. (2002). On the universality and cultural specificity of emotion recognition: A meta-analysis. Psychological Bulletin, 128(2), 203-235. https://doi.org/10.1037/0033-2909.128.2.203.

Francis, L. A., \& Susman, E. J. (2009). Self-regulation and rapid weight gain in children from age 3 to 12 years. Archives of Pediatrics and Adolescent Medicine, 163(4), 297-302. https://doi.org/10.1001/archpediatrics.2008.579.

Garner, P. W., Carlson Jones, D., Gaddy, G., \& Rennie, K. M. (1997). Low-income mothers' conversations about emotions and their children's emotional competence. Social Development, 6(1), 37-52. https://doi.org/10.1111/j.1467-9507.1997. tb00093.

Gavazzi, I. G., Ornaghi, V., \& Antoniotti, C. (2011). Children's and adolescents' narratives of guilt: Antecedents and mentalization. European Journal of Developmental Psychology, 8(3), 311-330. https://doi.org/10.1080/17405629.2010.491303.

Gottman, J. (2000). The emotional intelligence of children. Athens: Ellinika Grammata. (Original title: The Heart of Parenting).

Gottman, J. (2011). Raising an emotionally intelligent child. New York, NY: Simon and Schuster.

Housman, D., Denham, S., \& Cabral, H. (2017). Effectiveness of emotional cognitive social early learning (ECSEL) approach in building young children's emotional competence and self-regulation from birth. Manuscript in preparation.

"iYes Project." (2016). Retrieved from http://iyes-project.eu/index.php/iyes/iyes-background.

"KidsMatter: Social and Emotional Learning." (2017). Retrieved from https://www.kidsmatter.edu.au/ mental-health-matters/social-and-emotional-learning. 
Kremenitzer, J. P., \& Miller, R. (2008). Are you a highly qualified, emotionally intelligent, early childhood educator? Young Children, 63(4), 106-112.

Laughlin, L. (2013). Who's minding the kids? Child care arrangements: Spring 2011 (current population reports P70-135). Washington, DC: U.S. Census Bureau.

LeBuffe, P. A., \& Naglieri, J. A. (2012). The devereux early childhood assessment for preschoolers, second edition (DECA-P2): assessment, technical manual, and user's guide. Lewisville, NC: Kaplan Early Learning Company.

Leerkes, E., Paradise, M., O'Brien, M., Calkins, S., \& Lange, G. (2008). Emotion and cognition processes in preschool children. Merrill-Palmer Quarterly, 54(1), 102-124. https://doi.org/10.1353/mpq.2008.0009.

Mackrain, M., LeBuffe, P., \& Powell, G. (2007). The devereux early childhood assessment for infants and toddlers (DECA-I/T): assessment, technical manual, and user's guide. Lewisville, NC: Kaplan Early Learning Company.

Mayer, J. D., Roberts, R. D., \& Barsade, S. G. (2008). Human abilities: emotional intelligence. Annual Review of Psychology, 59, 507-536. https://doi.org/10.1146/annurev.psych.59.103006.093646.

McCabe, P. C., \& Altamura, M. (2011). Empirically valid strategies to improve social and emotional competence of preschool children. Psychology in the Schools, 48(5), 513-540. https://doi.org/10.1002/pits.20570.

McClelland, M., Acock, A., \& Morrison, F. (2006). The impact of kindergarten learning-related skills on academic trajectories at the end of elementary school. Early Childhood Research Quarterly, 21, 471-490. https://doi.org/10.1016/j. ecresq.2006.09.003.

McClelland, M., Ponitz, C., Messersmith, E., \& Tominey, S. (2010). Self-regulation: The integration of cognition and emotion. In R. Lerner (Series Ed.) \& W. Overton (Volume Ed.), Handbook of lifespan human development: Vol. 4. Cognition, biology, and methods (pp. 509-553). Hoboken, NJ: Wiley. https://doi.org/10.1002/9780470880166.hlsd001015.

Munns, E. (2015). Theraplay ${ }^{\circledR}$ : The use of structured play to enhance attachment in children. In C. E. Schaefer \& H. G. Kaduson (Eds.), Short-term play therapy for children (3rd ed., pp. 53-76). New York: Guilford.

Murray, D. W., Rosanbalm, K., \& Christopoulos, C. (2016a). Self-regulation and toxic stress report 3: A comprehensive review of self-regulation interventions from birth through young adulthood (Report \#2016-34). Washington DC: Office of Planning, Research and Evaluation, Administration of Children and Families, U.S. Department of Health and Human Services.

Murray, D. W., Rosanbalm, K.D., \& Christopoulos, C. (2016b). Self-regulation and toxic stress report 4: Implications for programs and practice (Report \# 2016-97). Washington, DC: Office of Planning, Research and Evaluation, Administration for Children and Families, U.S. Department of Health and Human Services.

Murray, D. W., Rosanbalm, K., Christopoulos, C., \& Hamoudi, A. (2015). Self-regulation and toxic stress: Foundations for understanding self-regulation from an applied developmental perspective (Report \#2015-21). Washington, DC: Office of Planning, Research and Evaluation, Administration of Children and Families, US Department of Health and Human Services.

National Scientific Council on the Developing Child. (2004). Children's emotional development is built into the architecture of their brains (Working Paper No. 2). Retrieved from http://www.developingchild.net.

National Scientific Council on the Developing Child. (2007a). The timing and quality of early experiences combine to shape brain architecture (Working Paper No. 5). Retrieved from http://www.developingchild.net.

National Scientific Council on the Developing Child. (2007b). A science-based framework for early childhood policy: Using evidence to improve outcomes in learning, behavior and health for vulnerable children. Retrieved from http://www. developingchild.net/pubs/persp/pdf/Policy_Framework.pdf.

National Scientific Council on the Developing Child. (2010). Persistent fear and anxiety can affect young children's learning and development (Working Paper No. 9). Retrieved from http://www.developingchild.harvard.edu.

Nelson, H., Kendall, G., \& Shields, L. (2013). Children's social/emotional characteristics at entry to school nurses. The Journal of Child Health Care, 17, 317-331. https://doi.org/10.1177/1367493512461458.

OECD's “Baby PISA" Early Learning Assessment. (2017). Retrieved September 8, 2017, from http://www.acei.org/ acei-news/2017/5/9/oecds-baby-pisa-early-learning-assessment.

OECD. (2011). Families are changing. In Doing better for families (17-53). Retrieved from http://www.oecd.org/els/ soc/47701118.pdf.

Perry, B. (2000). How the brain learns best. Instructor, 110(4), 34-35.

Saarni, C. (1997). Emotional competence and self-regulation in childhood. In P. Salovey \& D. Sluyter (Eds.), Emotional development and emotional intelligence: Educational implications (pp. 35-66). New York, NY: Basic Books.

Salmon, K., Evans, I. M., Moskowitz, S., Grouden, M., Parkes, F., \& Miller, E. (2013). The components of young children's emotion knowledge: Which are enhanced by adult emotion talk? Social Development, 22(1), 94-110. https://doi. org/10.1111/sode.12004.

Salovey, P., \& Mayer, J. D. (1990). Emotional intelligence. Imagination, Cognition, and Personality, 9, 185-211. https://doi. org/10.2190/DUGG-P24E-52WK-6CDG.

Samman, E., Presler-Marshall, E., Jones, N., Bhatkal, T., Melamed, C., Stavropoulou, M., \& Wallace, J. (2016). Women's work: Mothers, children and the global childcare crisis. In Early childhood matters. Retrieved from https://www.odi.org/ sites/odi.org.uk/files/resource-documents/10680.pdf.

Sauter, D. A., Eisner, F., Ekman, P., \& Scott, S. K. (2010). Cross-cultural recognition of basic emotions through nonverbal emotional vocalizations. Proceedings of the National Academy of Sciences, 107(6), 2408-2412. https://doi.org/10.1073/ pnas.0908239106.

Schore, A. N. (2003). Affect dysregulation and disorders of the self. New York, NY: Norton.

Schultz, B. L., Richardson, R. C., Barber, C. R., \& Wilcox, D. (2011). A preschool pilot study of connecting with others: Lessons for teaching social and emotional competence. Early Childhood Education Journal, 39(2), 143-148. https://doi. org/10.1007/s10643-011-0450-4.

Schunk, D. H., \& Pajares, F. (2009). Self-efficacy theory. In K. R. Wentzel \& A. Wigfield (Eds.), Handbook of motivation at school (pp. 35-53). New York, NY: Routledge.

Shonkoff, J. P., \& Phillips, D. A. (Eds.). (2000). From neurons to neighborhoods: The science of early childhood development. Washington, DC: National Academies Press. 
Siegel, D. J. (2012). The developing mind: How relationships and the brain interact to shape who we are (2nd ed.). New York, NY: Guilford Press.

Thompson, R. (2009). Doing what doesn't come naturally: The development of self-regulation. Zero to Three, 30(2), 33-38. Tobin, J. J., Wu, D. Y. H., \& Davidson, D. H. (1989). Preschool in three cultures: Japan, China, and the United States. New Haven, CT: Yale University Press.

Trevarthen, C. (2009). The function of emotion in infancy: The regulation and communication of rhythm, sympathy, and meaning in human development. In D. Fosha, D. J. Siegel, \& M. F. Solomon (Eds.), The healing power of emotion: Affective neuroscience, development, and clinical practice (pp. 112-114). New York: Norton.

Ursache, A., Blair, C., Stifter, C., \& Voegtline, K. (2013). Emotional reactivity and regulation in infancy interact to predict executive functioning in early childhood. Developmental Psychology, 49(1), 127. https://doi.org/10.1037/a0027728.

Vallotton, C., \& Ayoub, C. (2011). Use your words: The role of language in the development of toddlers'self-regulation. Early Childhood Research Quarterly, 26(2), 169-181. https://doi.org/10.1016/j.ecresq.2010.09.002.

Walker, A. K., \& MacPhee, D. (2011). How home gets to school: Parental control strategies predict children's school readiness. Early Childhood Research Quarterly, 26(3), 355-364. https://doi.org/10.1016/j.ecresq.2011.02.001.

What is SEL? (2016). Retrieved from http://www.C.org/what-is-sel/.

Wilson, K., Havighurst, S., \& Harley, A. (2012). Tuning into kids: An effectiveness trial of a parenting program targeting emotion socialization of preschoolers. Journal of Family Psychology, 26, 56-64. https://doi.org/10.1037/a0026480.

Winter, P., Ministerial Council for Education, Early Childhood Development and Youth Affairs (Australia), \& Early Childhood Services Ltd. (2010). Engaging families in the early childhood development story: Neuroscience and early childhood development: Summary of selected literature and key messages for parenting. Carlton South, Victoria: Ministerial Council for Education, Early Childhood Development and Youth Affairs.

Woodcock, R. W., McGrew, K. S., \& Mather, N. (2001). Woodcock-Johnson III ACH. Itasca, IL: Riverside Publishing.

Zins, J. E., Bloodworth, M. R., Weissberg, R. P., \& Wahlburg, H. J. (2007). The scientific base linking social and emotional learning to school success. Journal of Educational and Psychological Consultation, 17(2-3), 191-210. https://doi. org/10.1080/10474410701413145.

\section{Submit your manuscript to a SpringerOpen ${ }^{\circ}$ journal and benefit from:}

- Convenient online submission

- Rigorous peer review

- Open access: articles freely available online

- High visibility within the field

- Retaining the copyright to your article

Submit your next manuscript at $\boldsymbol{\nabla}$ springeropen.com 